\title{
Analysing How the Shift in Discourses on Social Media Affected the Narrative Around the Indian General Election 2019
}

\author{
Devansh Manu $^{1 *}$, Radhika Krishnan ${ }^{1}$, Ponnurangam Kumaraguru ${ }^{2}$ \\ ${ }^{1}$ International Institute of Information Technology, Hyderabad, India \\ ${ }^{2}$ Indraprastha Institute of Information Technology, Delhi, India
}

\section{ARTICLE INFO}

\section{Keywords:}

Elections

Social media

Discourses

Social computing

Twitter

\begin{abstract}
The Lok Sabha Elections 2019 in the world's largest democracy, India, was the biggest electoral event on the planet. These elections are key in the selection of the Prime Minister, the highest authority in the cabinet. Keeping in pace with the global trend, the Indian elections saw a very prominent use of Online Social Media by political parties to create a major discourse around the event. We focus our study on Twitter, collecting over 45 Million tweets, tracking more than 3500 hashtags and over 2500 political handles while monitoring their network interactions. In this work, we have analysed tweets from all these political handles to see how narratives were shaped and altered over time. We study these narratives formed by the party already in power and how they were supported or challenged by other parties. Spanning over 5 months, January to May 2019 , we analysed the monthly changes in the rhetoric created by the leading political parties and leaders. We then discern the impact of these changes on existing narratives during the campaigning and the elections.
\end{abstract}

\section{Introduction}

\subsection{Indian Political Framework}

India is the world's largest democracy in which the President is the head of the state and the Prime minister of India is the Head of the Government. The framework under which the politics operate consists of a central authority at the centre, and various state governments at its periphery. In this Bicameral legislative framework, there are two houses of the parliament, the Rajya Sabha which is the upper house of the parliament representing the state and the Lok Sabha which is the lower house of the parliament and represents the people of the country. The Lok Sabha, also known the House of People comprises of 545 members, of which 543 are elected from 543 constituencies around the country and the remaining 2 from the Anglo-Indian Community.

\subsection{Indian Politics, BJP and INC}

To understand the scenario of these elections in a better way, we can have a brief look at the political history of the nation. The Indian National Congress (INC) was formed in 1885, when India was under the British rule. Ever since it was formed, its agenda remained independence of the country from the English. Spanning over 6 decades, the struggle finally came to an end when in 1947 India celebrated its independence. Ever since then, the INC has had a strong dominance over the Lok Sabha until 2014 when the lost the elections by a huge margin. Even until 2014, there were small periods like 1977-1980, 1989-1991 and 1996-2004 when the party

* Corresponding Author E-Mail Address: devanshmanu@gmail.com 
was out of power, but the 2014 defeat by the Bhartiya Janata Party, was a huge hit on its political dominance.

The next biggest political party in India is the Bhartiya Janata Party (BJP) which was formed in 1980, as a representative of the Hindu majority in the country. It emerged out as a political wing the right-wing Hindu nationalist volunteer organization - the Rastriya Swayamsevak Sangh, popularly known as the RSS. As of 2019, the BJP is the biggest political party in the world in terms of primary membership. The BJP is the leader of the National Democratic Alliance (NDA) that defeated INC from power from 1998-2004. As also mentioned earlier, in 2014 the BJP defeated the INC with a huge margin and won an overall majority in the Lok Sabha with 282 seats.

\subsection{General Elections 2019}

Conducting elections in the planet's second most populous country, is a massive and complex affair. As for the 2019 Indian General elections, a total of 900 Million people were eligible to vote. This year also saw the highest voter turnout ever recorded in the country with almost $67 \%$ of the eligible voters voting for their representatives (Jain, 2019). Given this huge number, elections were conducted over 7 phases starting from $11^{\text {th }}$ April 2019 to $19^{\text {th }}$ May 2019. All the votes were counted on $23^{\text {rd }}$ May 2019 giving a massive victory to the Bhartiya Janata Party (BJP) with 303 seats in the Lok Sabha and Narendra Modi was sworn in as the Prime Minister for the $2^{\text {nd }}$ consecutive tenure after 2014 .

\subsection{Discourses set in the 2019 elections}

Although the 2014 Elections saw BJP win the mass support by tackling issues like development, corruption and black money, the discourses that were set for the 2019 Elections were completely different. Owing to the weak presence of the left-wing parties at the centre, issues like nationalism, national security and economic reforms contributed to BJP's massive victory. The 2019 elections also marked a failure of the well-balanced national two-party system in the country. A huge discourse among the public was "If not Modi, then who?" (Puskarna, 2019). Hence the absence of a "viable political alternative" in many states, made a strong narrative against the Indian National Congress (Sharma A, 2019).

\subsection{Importance of the 2019 elections}

In 2019, India witnessed an Election like never before. It wasn't simple a fight of BJP continuing to stay in power or the INC coming back in power, it was much more than that. And this difference was not solely on a political front. The voter base for this election is much more literal, skilful and way more tech-savvy (Katju, Election Campaigning in a transformed India, 2019). There is also a stark reduce in the share of agriculture in the GDP (Statistics Times 2019) and a major shortage of secure employment. With 45 Million young voters registered to vote for the first time, this election was a very youth-focussed one (Tiwari, 2019).

Given these situations, it was tough play for both the parties. On one hand, it was a do-or-die situation for the Congress (Ayoob, 2019) owing to the start of its decline after the 2014 General Elections. On the other hand, a win for the Bhartiya Janata Party would have given them allround hegemonic control over all state institutions and public discourse (Mukhopadhyay, 2018). Although the 2014 elections saw a Modi wave that no one could even come near to, this election had different plans for the BJP. The recent years saw a decline in Modi's popularity in the small and middle-class section of the nation, primarily owing to demonetization and GST.

It is because of this that the campaign strategies adopted by both the parties were poles apart. Contrary to what is believed, the 2019 election campaign is an ideological one: Hindu ultraright-wing nationalism is pitted against secular, inclusive and tolerant values that defend free speech and minority rights (Katju, Election Campaigning in a transformed India, 2019). 
The Bhartiya Janata Party, a Hindutva right-wing party, focussed on religious grounds, side lining various social, economic and political agendas. This was very different from their campaign in 2014 with the NDA alliance, that had development and growth as the defining features. Moreover, there was a wave to end INC's corrupt practices, bring back the black money and create new jobs. This was the basis on which the brand Modi was created. The rhetoric set in the 2019 elections was very, very different. It was primarily based on communal grounds, and the campaign focused on issues like national security and terrorism. All this was paralleled with the "Modi" brand, making it a very leader-centric campaign.

For the Indian National Congress on the other hand, the campaign strategy was completely different. It focused on issues like unemployment, agrarian distress and corruption. Following a very idealistic campaign, it also focused on secularity and inclusiveness in its campaign agenda and also created discourses that were anti brand Modi.

\subsection{Social Media and Elections}

The Social Media today, is playing a very important role in the politics of almost every nation. The use of social networks to expand a party's reach and impact more and more voters through an online media was first seen in the 2008 U.S Presidential elections. Barack Obama's exceptional online campaign on Facebook surely helped him win the votes of the young audience who are today very active on social media (Meti V., 2015). This campaigning strategy revolutionized political campaigning structures across the globe. Obama's campaign took on the characteristics of a social movement with a strong digital grassroots mobilization (Bimber, 2014) .

Ever since then, social media has started playing a key role in politics. This doesn't only confine to campaigning - but to political and social movements (Gangopadhyay, 2015), political protests (Jost, 2018), mass mobilisation (Shaw, 2016), as well as journalism (Bruns, 2019) around the world.

In India, there has been a boom in social media political campaigns, which was more, marked in the 2014 General Elections. Both the major political parties used social media to promote their manifestos and interact in the public domain in a one-to-one manner. They analysed different views the people had and worked on them. Home Minister Rajnath Singh, in a seminar after the 2014 general elections, also said that "Through social media, the government is outlining its plan, its vision". After assuming power, the NDA government has been using Twitter, Facebook and blogs to outline its plans, vision and various messages. A major reason for this was to involve and cater to the interest of the youth population of the country, that are active on most of the social media websites. Owing to this, political parties invested huge amounts of their funds into social media campaigning, hence also increasing their reach.

While the 2014 elections saw a gradual rise in the importance of social media in elections, the 2019 was far ahead. The 2019 General Elections saw social media playing a crucial and deciding role in various spheres before the during the elections. All major political parties invested huge manpower as well as money power in their social media engagement. Political parties have also spent over ₹53 crore on digital platforms like Google and Facebook between February and May, with the BJP accounting for a lion's share of the spending (PTI, BJP tops political advertisement spend on Facebook, Google in Feb-May, 2019). The 2019 Lok Sabha elections have been dubbed as India's first 'WhatsApp elections', taking into consideration the impact, mobilisation and spread of fake news on the 200 million-strong messaging platform (Hari, 2019). The crucial role that social media played during the 2019 elections can be validated by the fact that the Elections Commission of India, for the first time, issues social media guidelines for all the candidates contesting the election (Document, 2019). Apart from this, all the candidates had to submit their social media details while submitting their candidature. 
The extent of technological penetration in the Indian market is proven by the more than 350 Million smartphone users in India. Moreover, the 2019 elections also saw a highest number of first-time voters.

Most of these 350 Million are the young generation in their 20s who are actively involved in various online discussions around politics. Of all the social media platforms, Twitter is one of the most popular platforms for politicians, media houses and general people.

\section{Methodology}

\subsection{Data Collection}

We have collected over 45 million tweets during the campaigning phase and elections period in 2019 that cover discourses that were around elections. The first approach towards this data collection was a hashtag-based collection where the Twitter API was queried based on a manually curated list of hashtags. This list was updated regularly to make sure that we don't miss out on any trending hashtags that would be relevant to elections. The most prominent hashtag across the entire period was undoubtedly \#loksabhaelections2019.

We also manually curated a list of 2580 twitter handles who were politically relevant. All the tweets by these handles were regularly tracked and collected through official twitter APIs. We also annotated the party affiliations of each of these handles to have a clearer picture of how the discourses were shaped, who shaped them and which parties they belonged to. Apart from these just tweets, we also captured daily snapshots of user data of handpicked verified political handles to understand the network interactions and user behaviours.

We extracted twitter handles of candidates contesting in the elections for the official website of the Election Commission of India (ECI) where all the candidates must mandatorily fill in their social media handles while filing their nomination. Out of the 8,055 candidates who stood for elections, we found that 1,012 were active on Twitter. Of these 1,012 handles, $31.93 \%$ of the handles were verified. This helped us verify the authenticity of these handles. Table 1 shows an exact description of the data.

Table 1.

Data Collection Statistics

\begin{tabular}{ll}
\hline Number of & Count \\
\hline Tweets collected & $45,177,116$ \\
Active Users & $2,150,179$ \\
Average tweets per user & 21.01 \\
Political Handles & 2580 \\
Politicians on Twitter & 1,012 \\
Verified Politicians & 323 \\
\hline
\end{tabular}

\subsection{Discourses on Twitter}

Twitter gives various political organizations and political leaders, a platform to voice their opinion, broadcast information and take part in online discussions and debates. Moreover, it serves as a strong framework to provide a two-way communication directly with the public during the campaigns as well as elections. The way information spreads out, guarantees that the content is spread through a network of interconnected users, rather than just limiting it between a few users (Boyd, 2010) This strategy surely allows politicians to create a discourse around the elections, just by the kind of content they post, and the way the interact with other users on the twitter network.

Our study focused on analysing what kind of discourses were created by the party already in power, and how they were challenged or supported by the other parties. This was done on a monthly basis from January 2019 to May 2019. These months were chosen for the study because January is when hashtags relevant to Lok Sabha Elections 2019 started to trend and 
people started talking about elections. Soon after this, the parties released their manifestos and started the campaigns in full swing. A month-wise analysis also helped us understand how the narratives were shaped up over months by several parties and how different parties reacted to such narratives created. In this study we focus our analysis on the two biggest political parties in the country - BJP, the party presently in power and INC, the primary opposition party.

\subsection{LDA Topic Modelling}

Once we had the tweets by BJP and INC segregated by month, the next step was to perform a topic modelling on the collected data to identify and summarize the main topics that appear in the textual corpus. The first technique that is majorly used in the field of data science for topic modelling is LDA Topic modelling. Latent Dirichlet allocation (LDA) topic modelling is useful to classify text in a document to a particular topic.

After analysing these results carefully, we can see that the Topic modelling does not particularly work well for the kind of data that we had. The primary reasons for this was that the language used in the tweets are a mix of English, Hindi, Hinglish and code-mix. Moreover, the sentences are not normalised and not structured in a regular manner. Since the tweets have a character limit, users often tend to use abbreviations and shortened spellings of words. Hence these results were not as one would expect. The next approach to this was a simple term-frequency based word cloud generation.

\subsection{Word Cloud Analysis}

To get a broad overview of how these conversations were shaped, we choose to perform a word cloud analysis. A word cloud is a visual representation of the word frequency in a document. In this visual representation, the word which occurs with a higher frequency is shown in a larger size than the word that occurs with a lower frequency. This frequency-based word cloud approach is very useful in visually summarizing large amount of textual data. These word clouds help us understand what is the crux of the text that we are analysing at a very intuitive level. However, we should keep in mind that this approach only focusses on the term frequency and completely let's go of the context in which that word occurs. Hence, we cannot summarize the document using a word cloud, but we can get a sense of what is being talked about more in that document. Word clouds generated for a body of text can serve as a starting point for a deeper analysis (Heimerl, 2017).

We generated these word clouds using the Python word cloud library with additional functionality added. This additional functionality was crucial to allow the word cloud generator to handle the Devanagari script. India's first official language, Hindi, is written in the Devanagari script. These word clouds were created using the term frequencies, with the size of the word assigned by its frequency rank.

\section{Monthly Analysis of Tweets from January'19 to May'19}

To understand how the online discourses were shaped by the BJP and INC in the General Elections 2019, we analysed the tweets collected, on a monthly basis. We first sorted the tweets by their party affiliations of the handles posting them (i.e. either BJP or INC) and then sorted them by the month they were posted in. From this collected data of tweets posted by handles affiliated to BJP and INC we created monthly word clouds to get a broad idea of what topics are being discussed in these tweets. This content is actually what forms and narrative online. When we further compare these monthly word clouds, we can get a clearer picture of how the discourses have changed over the months. 

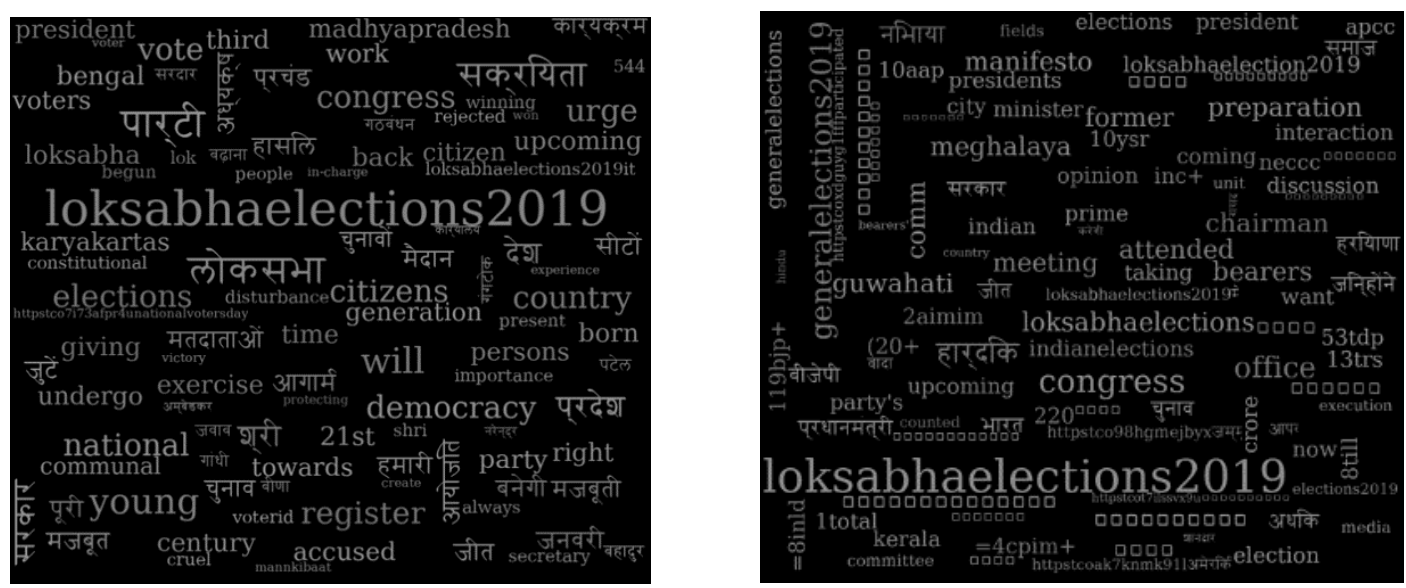

Figure 1. January Tweets for i) BJP and ii) INC

January 2019 was the month when tweets with the hashtag "\#loksabhaelections2019" started surfacing up on the micro-blogging website - Twitter. The word cloud for tweets posted by BJP clearly shows a high occurrence of the words loksabhaelections2019 and लोकसभा. Other words that are similar to elections as well was voting are - gathbandhan, junaav, matdaan, democracy and voterid. No other topic of interest really shows up big in this month. A few other words with fair frequency were Bengal and karyakarta. This points to Mamta Banerjee's Mega opposition rally in January 2019 and Prime Minister Modi's meeting with the party karyakartas (workers) before the campaign for the elections begins in full swing.

The word cloud for January for tweets posted by INC political handles is very sparse, unlike the one for BJP. Although the word loksabhaelections2019 does surface up in decent numbers, there is no other topic or issue that shows up significantly. Some words that are related to the elections broadly are - indianelections, generalelections, manifesto etc.

- February 2019
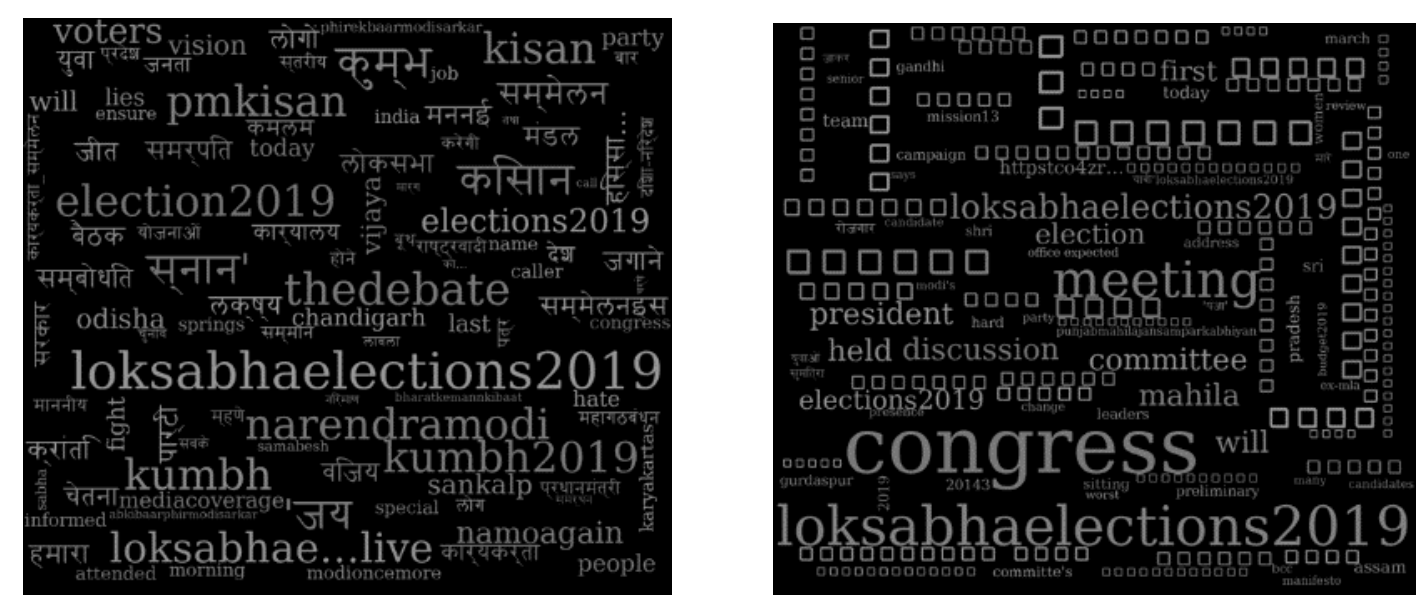

Figure 2. February Tweets for i) BJP and ii) INC

BJP's word cloud for February 2019 gives a much better look as compared to the previous month. This month too, the highest occurring word is loksabhaelections2019, which is obvious as that would be one keyword present in almost all tweets for a much better reach and audience. We also see mentions of words like kisan, pmkisan and किसान. This clearly points to the PM- 
Kisan Scheme launched by Narendra Modi on $24^{\text {th }}$ February. The Kumbh Mela was also organised in the same month with PM Modi also taking a dip in the holy Ganges before the elections - termed as the shahi snaan. As the elections were approaching, we also see a clear Modi wave coming up even in the online space with words like modioncemore, namoagain, narendramodi, phirekbaarmodisarkar, abkibaarphirmodisarkar etc. coming up very frequently. In an attempt to question the current government before the manifestos are released - INC's Rahul Gandhi also asked Modi for a 5 min debate on a public space.

Very similar to January, INC's word cloud for February is sparse too. Although one significant observation here is that the word congress appears more than loksachaelections2019. This is also the first word cloud that we see where most of the words are not in English (Roman script) / Hindi (Devanagari script). This really helps the politicians increase their reach for the Indian audience where there is not one language spoken by everybody. Increasing use of Hindi and regional languages has moved towards breaking the notion of social media as a form of elite outreach and also reach to the local audiences (Pal, 2018). Other words that surface up are president and held discussion which refers to a meeting Rahul Gandhi held in the same month with all the general secretaries to discuss micro-level booth management during elections. We also see a mention of mahila indicating the FIR filed by the Mahila Congress against derogatory remarks on Priyanka Gandhi entering the electoral space.

- March 2019
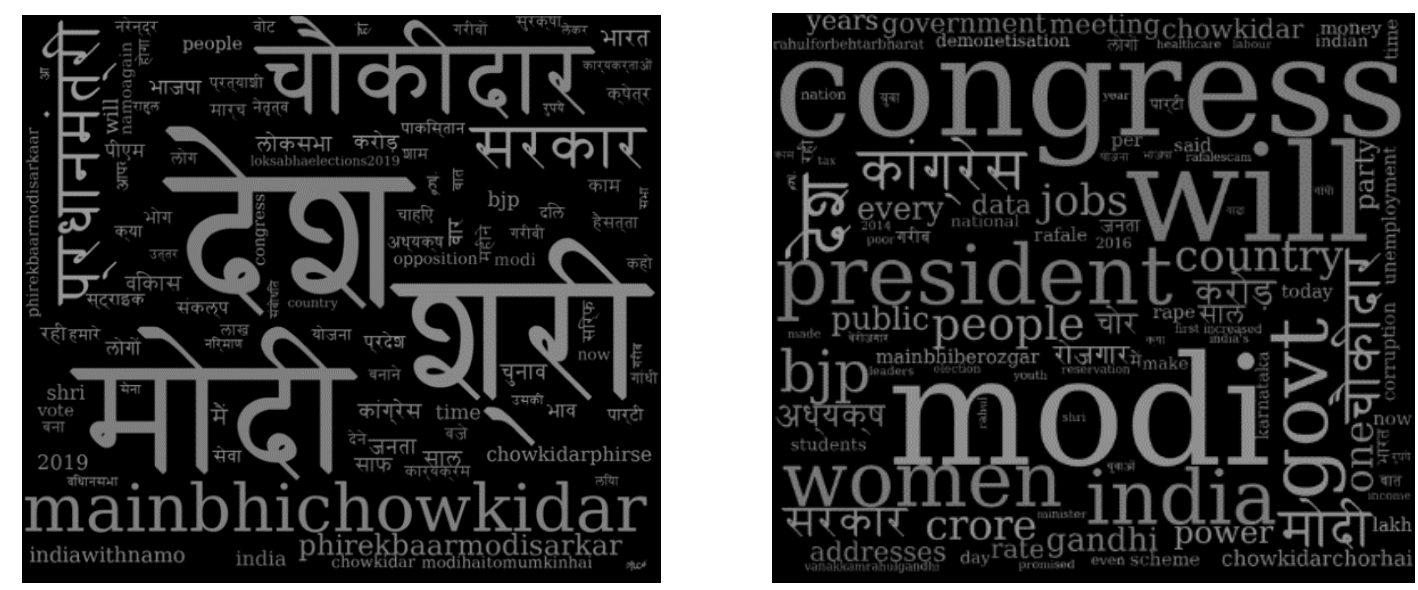

Figure 3. March Tweets for i) BJP and ii) INC

Narendra Modi has previously called himself a chowkidar for the nation during the previous elections but after the government was criticised for the Rafale scam, Rahul Gandhi coined the term for the Modi - "Chowkidar chor hai". On 14 ${ }^{\text {th }}$ March 2019 Narendra Modi started the "Main bhi chowkidar" campaign across the nation as a response to the opposition. This campaign rapidly gained popularity across all BJP supporters and can be rightly called the BJP's first online campaign strategy for the 2019 elections. Soon after the campaign waved out, BJP politicians as well as millions of BJP supported added the word "Chowkidar" to their name on Twitter. The popularity of this campaign can clearly be seen in BJP's word cloud with words like चौकीदार, mainbhichowkidar, chowdikaarphirse etc. occurring in high numbers. Apart from this, the most occurring word is - मोदी - a clear indication of the strong modi wave in the country the popularity of the leader. This is supported by words like modi, indiawithnamo, phirekbaarmodisarkar, modihaitohmumkinhai, pradhanmantri etc. Other topics that come up are - garibi - in reference to Rahul Gandhi's garibi hatao yojana and Pakistan - in reference to the airstrikes by the Indian air force in late February. Apart from this, there is also a slight 
mention of vikas (development) - one of the first topic that public interest that shows up in 3 months.

The word cloud for INC for March, unlike January and February, is not sparse and the first look also indicates the presence of various words of electoral importance. Surprisingly, unlike all other word clouds of BJP and INC so far, the keyword loksabhaelections 2019 does not occur in high numbers. Modi is the most commonly word used - criticising this government for the previous 5 years for failure in achieving what is promised. As an ideal democratic behaviour, the principal opposition - INC criticised the current BJP government on various issues concerning the public and nation, some of them being - jobs, Rafale scam, corruption, unemployment, youth, healthcare, demonetisation etc. The INC also promised creation of new jobs for the unemployed population of the country as well as having a 33\% job reservation for women. Taking a shot on demonetisation, Rahul Gandhi also launched the NYAY yojana to remonetize what Modi demonetized (PTI, Nyay scheme with 'remonetise' what Modi 'demonetised' says Rahul Gandhi, 2019). This was also the month when Rahul Gandhi launched the "chowkidar chor hai" and "main bhi berozgar" campaign aimed that PM Modi. Priyanka Gandhi's first rally after entering the 2019 political arena was also held during this time. Lastly, to create a similar trend like the Modi wave, we also see a slight mention of hashtags like rahulforbehtarbharat.

- April 2019
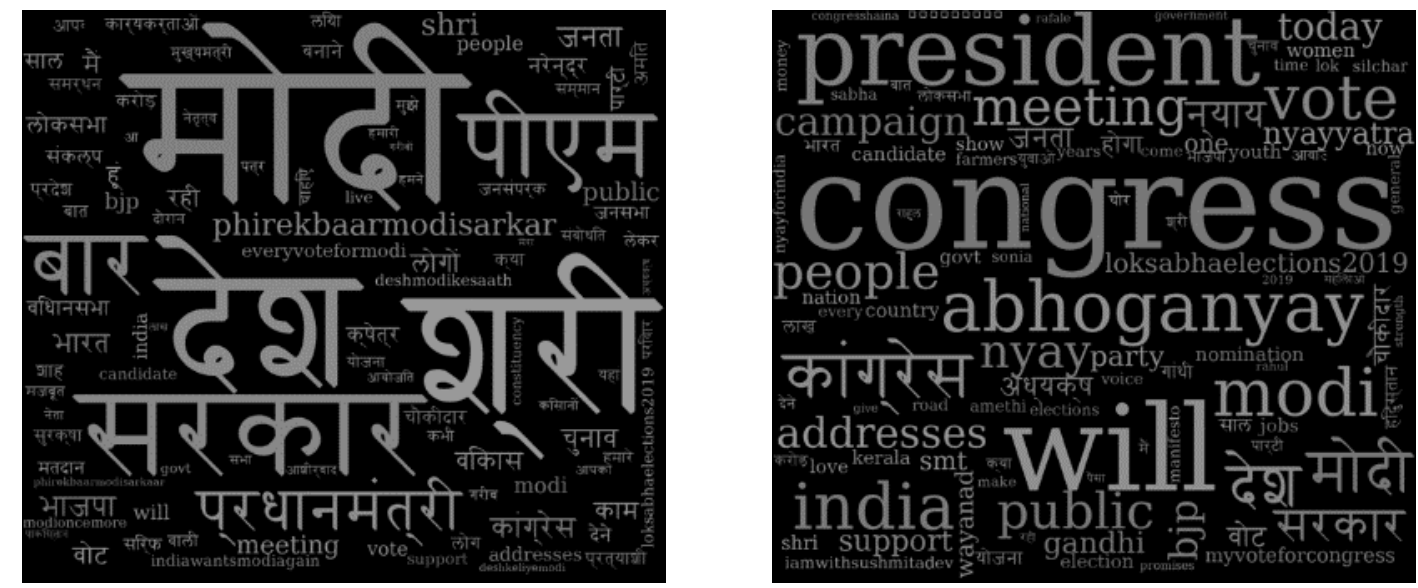

Figure 4. April Tweets for i) BJP and ii) INC

April was the month when the voting process for the 2019 Elections started. This election was planned to be conducted in 7 phases starting from $11^{\text {th }}$ April 2019 to $23^{\text {rd }}$ May 2019. Very similar to March, BJP's word cloud also shows a really high mention of the word modi. As the Modi wave continued amongst the voters, new hashtags were introduced and became trending. Some of them being - phirekbaarmodisarkar, everyvoteformodi, deshmodikesath, indianwantsmodiagain, deshkeliyemodi, modioncemore, modioncenter etc. Vikas and garibtwo more topics are public interest come up in this month. There is also a clear reduction in the keywords related to chowkidar in this month - it was a wave that came up for a short span, and people stopped tweeting about it after they changed their names on Twitter.

It just before the elections in April 2019 that the INC launched the NYAY Yatra to provide economic and social justice to poorer sections of the society. The hashtag abhoganyay was used to gain support for this agenda. Even in this month we see a very low use of generic hashtags related to loksabhaelections 2019. Contrary to the BJP, we see mentions of issues like farmers, youth, Rafale scam and women. There are mentions of Rahul Gandhi's roadshow in Wayanad - the constituency from where he filed his nomination. Again, there are some hashtags like 
congresshaina and myvoteforcongress which are trending to increase the popularity and reach of the Congress among the public. But unlike the BJP, none of them could actually sustain for long (Alawadhi, 2019).

- May 2019
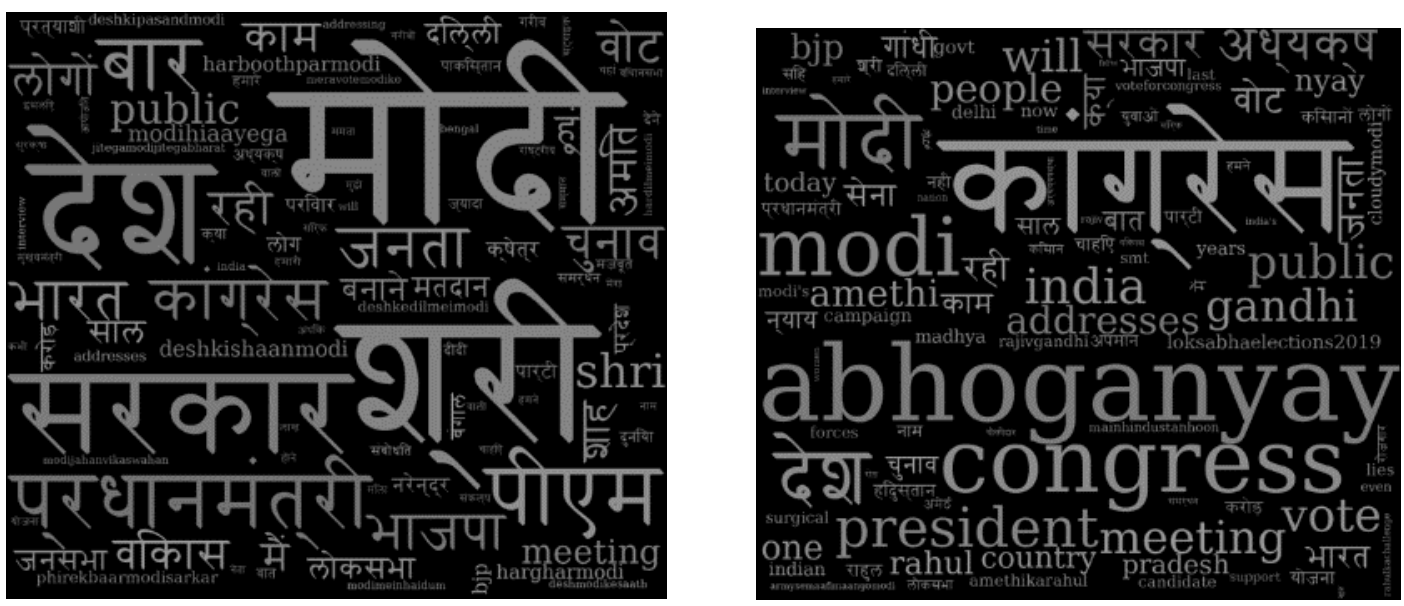

Figure 5. May Tweets for i) BJP and ii) INC

The results for the Indian General Elections 2019 were declared on the $23^{\text {rd }}$ May 2019 and BJP marked a glorying victory winning 303 out of the 543 seats in Lok Sabha. It is strongly believed that Narendra Modi himself led BJP to this landslide victory. Modi created a strong discourse and made this an election all about himself (Biswas, 2019). It was hence that the May word cloud for BJP clearly shows a very strong and prominent Modi wave on the social media. Almost all the words that appear with a significant frequency, are about Modi - modi, harboothparmodi, deshkipasandmodi, meravotemodiko, modihiaayega, jitegamodijitegabharat, hargharmodi, deshmodikesath, phirekbaarmodisarkar, deshkishaanmodi, deshkedilmemodi, hardilmemodi, modijahanvikasvahan, modimeinhaidum etc.

Keeping in trend with the tweets of all the previous months by INC, May too, saw a very low use of hashtags around loksabhaelections 2019. The NYAY Yojana supported by the abhoganyay hashtag seemed to gain support in this month too. Attacking the BJP on its major political agenda of National Security, P. Chidambaram also mentioned that "Modi insulting Army by disputing six surgical strikes" (PTI, Modi insulting Army by disputing six surgical strikes, 2019). Hence, we also see a few mentions of the term surgical. Again, there are some hashtags like amethikarahul, mainhindustanhoon, rahulkachallenge and voteforcongress which are trending to increase the popularity and reach of the Congress among the public.

\section{Conclusion}

As a conclusion we can say that the discourses formed on Twitter by both the major political parties - Bhartiya Janata Party and Indian National Congress, we're very divergent. On one hand where tweets posted by handles affiliated to BJP focus primarily on the "Modi brand", the tweets posted by INC handles focus on various issues of public interest like women, jobs, unemployment, demonetisation etc.

Towards the latter half of the election campaign season, INC launched its "Ab Hoga Nyay" campaign as a promise to curb poverty, create more jobs and provide a minimum income guarantee for the public. It can be seen, that till the very end, this campaign was carried forward by just one hashtag \#AbHogaNyay. The paramount online campaign for BJP was "\#PhirEkBaarModiSarkar", taking advantage of the highly popular figure of Narendra Modi. 
Unlike INC's campaign, this campaign was not propagated by just one hashtag but multiple hashtags like harboothparmodi, modihiaayega etc. to name a few. An important point to note here is that INC's campaign was actually focussed on one political agenda - an ideal behaviour in democracy whereas BJP's campaign was just focussed on Modi's popular image and the party getting back in power - with no mention of a political agenda.

Another interesting phenomenon to study here is the "Chowkidar" campaign by both the parties. The INC first started the Chowdikar campaign in March 2019 when Rahul Gandhi raised slogans of "Chowkidar Chor hai" against Prime Minister Narendra Modi. A few days later, Narendra Modi responded to this attack by the "Main Bhi Chowkidar" campaign. BJP's campaign which was started after INC's campaign in turn gained more popularity and actually backfired for the Congress. This can be clearly seen in the word clouds for March 2019 where the term frequency for MainBhiChowkidar surpasses that of ChowkidarChorHai by huge numbers.

The use of hashtags similar to "\#LokSabhaElections 2019" sharply reduced for both the parties after February 2019. This is interesting to note because this hashtag was officially launched by Twitter India's official handle to create focussed communications around the Elections (Desk, 2019). As observed from the word clouds of BJP and INC together, we can see that handles affiliated to BJP tweets more in Hindi, India's first official language, as opposed the INC handles. Apart from all the political topics of discussion, while INC handles mention "Congress" very frequently, the BJP handles rather mention "Modi". This gives a clear picture of how Modi is single-handedly leading the party towards the victories.

\section{References}

Alawadhi, N. (2019, April 13). In pitched battle of social media hashtags, Modi edges past Congress. Business Standard.

Ayoob, M. (2019, May 24). It's now a do-or-die situation for the Congress. The Hindi.

Bimber, B. (2014). Digital Media in the Obama Campaigns of 2008 and 2012: Adaptation to the Personalized Political Communication Environment. Journal of Information Technology \& Politics(10.1080/19331681.2014.895691), 11. 130-150.

Biswas, S. (2019, May 24). How Narendra Modi has reinvented Indian politics. $B B C$.

Boyd, D. G. (2010). Tweet, Tweet, Retweet: Conversational Aspects of Retweeting on Twitter. 43rd Hawaii International Conferences on System Sciences.

Bruns, A. N. (2019). Political Journalists and their social media audiences. Journalism and Social Media: Redistribution of Power?, 7, p. 1.

Desk, I. T. (2019, March 22). Twitter India Launches Lok Sabha Elections 2019 emoji in 12 languages. India Today.

Document. (2019, March 20). Voluntary code of Ethics for the 2019 General Elections. Election Commission of India.

Gangopadhyay, S. (2015). Digital Media and Social Movements.

Hari, V. (2019, May 25). Lok Sabha Elecitons 2019: The social media factor. The Week.

Heimerl, F. L. (2017). Word Cloud Explorer: Text Analysis based on word clouds.

Jain, B. (2019, May 21). Lok Sabha elections: At 67.1\%, 2019 turnout's a record, Election Commission says. Times of India. 
Jost, J. B. (2018, February). How Social media facilitates political protest: Information, motivation and social Networks. Advances in Political Pschycology, 39(S1).

Katju, M. (2019, June 09). Election Campaigning in a transformed India. The India Forum.

Katju, M. (2019, June 09). Election Campaigning in a transformed India. The India Forum.

Meti V., K. P. (2015). Social Media for Political Mobilization in India: A Study. J Mass Communication Journal, 5:275(10.4172/2165-7912.1000275).

Mukhopadhyay, N. (2018, November 24). Why the 2019 election may be the most crucial in India's history. Aljazeera.

Pal, J. B. (2018, June 23). Is Tweeting in Indian Languages Helping Politicians Widen Their Reach? Economic and Political Weekly, 53(25).

PTI. (2019, March 28). Nyay scheme with 'remonetise' what Modi 'demonetised' says Rahul Gandhi. Business Standard.

PTI. (2019, May 19). BJP tops political advertisement spend on Facebook, Google in Feb-May. The Hindu.

PTI. (2019, May 5). Modi insulting Army by disputing six surgical strikes. The Times of India.

Puskarna, V. (2019, April 08). Lok Sabha 2019 Elections: If not Modi as PM, then who? . The Week.

Sharma A, D. D. (2019, August 03). How can left politics in India be reclaimed? Economic and Political Weekly, 54(31).

Shaw, A. (2016, June). Role of Social Media in Social mobilization. Global Media Journal Indian Edition, 7(Summer), p. 1.

Tiwari, S. (2019, February 20). Data check: 45 million new, young voters could play a key role in 2019 elections. Scroll. 